\title{
EVALUASI PELAKSANAAN SISTEM PELAPORAN REKAM MEDIS DI KLINIK ASRI MEDICAL CENTER
}

\author{
Tri Handayani ${ }^{1}$, Ery Rustiyanto ${ }^{2}$, Djariyanto ${ }^{3}$, Suryo Nugroho Markus ${ }^{4}$ \\ Program Studi RMIK, Poltekes Permata Indonesia ${ }^{1,2,3,4}$ \\ Rekmedis_persia@yamail.com
}

\begin{abstract}
ABSTRAK
Evaluasi pelaporan di sarana pelayanan kesehatan sangatlah diperlukan salah satunya untuk mengetahui mutu dari pelayanan kesehatan yang diberikan oleh pihak pemberi pelayanan kesehatan. Melakukan evaluasi pelaksanaan sistem pelaporan rekam medis di klinik Asri Medical Center Tahun 2012.

Penelitian ini menggunakan metode penelitian deskriptif dengan pendekatan kualitatif. Jenis pelaporan di klinik Asri Medical Center belum sesuai dengan Permenkes RI no 1171 Tahun 2011. Alur penyusunan pelaporan sudah sesuai teori. Terdapat beberapa permasalahan dalam penyusunan pelaporan rekam medis. Hasil evaluasi sistem pelaporan dapat dilihat dari segi input (kebijakan/SOP, pendanaan, sumber daya manusia, organisasi/ manajemen, dan teknologi), proses (indikator, sumber data, pengumpulan, pengolahan, penyajian dan analisa data), dan output (hasil informasi dan pemanfaatan untuk pengambilan keputusan).

Evaluasi sistem pelaporan di klinik Asri Medical Center, dari segi input di klinik Asri Medical Center sudah ada SOP penyusunan laporan namun belum ada juknis penyusunan laporan, dari segi pendanaan tidak diberikan dana secara langsung, namun diberi fasilitas untuk menyusun laporan, petugas rekam medis sudah memahami cara menyusun pelaporan namun petugas front office belum memahami, struktur organisasi di unit rekam medis belum ada, dari segi teknologi sudah memanfaatkan billing system dalam menyusun laporan. Evaluasi dari segi proses, indikator rawat inap belum efisien, sumber data penyusunan laporan sudah sesuai dengan teori, pengumpulan, pengolahan, penyajian dan analisis data sudah dilakukan namun analisis data belum sesuai teori. Dari segi output, pengiriman laporan KDRS belum tepat waktu, laporan yang dibuat belum akurat dan lengkap, pengambilan keputusan sudah memanfaatkan laporan.
\end{abstract}

Kata Kunci: Evaluasi, Sistem Pelaporan, Klinik

\section{PENDAHULUAN}

Kebutuhan akan data dan informasi saat ini berkembang sangat pesat, dilihat dari segi kuantitas maupun kualitasnya. Dengan telah berlakunya Undang-Undang Nomor 14 Tahun 2008 tentang Keterbukaan Informasi Publik (KIP) maka tersedianya data dan informasi mutlak dibutuhkan terutama oleh badan layanan umum seperti rumah sakit dan pelayanan kesehatan yang lain.

Berdasarkan Undang-Undang Nomor 28 Tahun 2011 pasal 26 huruf c tentang klinik, penyelenggara klinik wajib melakukan pencatatan terhadap penyakit tertentu dan melaporkan kepada Dinas Kesehatan Kabupaten /Kota dalam rangka pelaksanaan program pemerintah. Pencatatan dan pelaporan yang dilakukan oleh pemberi pelayanan kesehatan dilakukan dalam rangka meningkatkan efektifitas pembinaan dan pengawasan pelayanan kesehatan di Indonesia. Pengiriman pelaporan yang tepat waktu akan sangat membantu dalam meningkatkan efektifitas pembinaan dan pengawasan pemberi pelayanan kesehatan. Penyusunan pelaporan dapat dilakukan oleh seorang perekam medis.

Agar pengambilan keputusan tepat sasaran, maka diperlukan evaluasi pelaporan di sarana pelayanan kesehatan. Tujuan evaluasi pelaporan antara lain untuk mengetahui sejauh mana perkembangan dari pelayanan kesehatan yang telah diberikan kepada pasien dalam kurun waktu tertentu, di semua bagian /unit masing-masing apakah mengalami peningkatan atau penurunan. Untuk itu evaluasi pelaporan di sarana pelayanan kesehatan sangatlah diperlukan salah satunya untuk mengetahui mutu dari pelayanan kesehatan yang diberikan oleh pihak pemberi pelayanan kesehatan (Rustiyanto, 2010). 
Tri Handayani, dkk. Evaluasi Pelaksanaan Sistem Pelaporan Rekam Medis

Berdasarkan studi pendahuluan yang dilakukan oleh peneliti pada bulan November 2012 di Klinik Asri Medical Center, terdapat beberapa permasalahan dalam sistem pelaporan yang ada. Menurut hasil wawancara dengan petugas rekam medis di klinik Asri Medical Center belum pernah melakukan pelaporan ekstern ke Dinas Kesehatan Kabupaten /Kota. Pelaporan kunjungan pasien rawat jalan dibuat oleh bagian front office dimana petugasnya tidak memiliki background pendidikan rekam medis. Pelaporan kunjungan pasien Unit Gawat Darurat (UGD), terkadang terdapat selisih antara pihak keuangan dan pihak rekam medis, hal ini dikarenakan pelayanan rekam medis belum dilakukan 24 jam sehingga bila ada pasien UGD pada malam hari setelah pelayanan rekam medis tutup identifikasi pasien dilakukan oleh perawat/dokter jaga, terkadang perawat /dokter jaga lupa melapor bahwa ada pasien UGD yang periksa dan terkadang tanggal periksa tidak diisi sehingga menyulitkan bagian rekam medis untuk membuat pelaporan. Penyusunan laporan rawat inap belum menggunakan sensus harian rawat inap. Laboratorium Patologi Anatomi (Lab. PA) di Asri Medical Center (AMC) belum memiliki sistem billing sendiri, sehingga ketika ada pasien rujukan dari RS PKU Muhammadiyah Yogyakarta yang melakukan uji laboratorium di Asri Medical Center masuk ke laporan kunjungan Asri Medical Center, padahal bukan pasien Asri Meical Center. Berdasarkan permasalahan tersebut, peneliti tertarik untuk melakukan evaluasi pelaksanaan sistem pelaporan yang ada agar pelaporan yang dihasilkan dapat bermanfaat dalam pengambilan keputusan manajemen.

\section{METODE}

Penelitian ini merupakan penelitian deskriptif dengan pendekatan kualitatif. Penelitian dilakukan di klinik Asri Medical Center Yogyakarta dengan subjek penelitian satu orang petugas rekam medis, satu orang petuga front office, dan satu orang sekretaris medis.

Variabel penelitian meliputi evaluasi pelaksanaan penyusunan pelaporan sebagai variabel bebas dan sistem pelaporan sebagai variabel terikat. Pengumpulan data dilakukan dengan wawancara mendalam, observasi, studi dokumentasi dan catatan lapangan. Instrumen pengumpulan data pada penelitian ini meliputi pedoman wawancara, cek list observasi, tape rekorder, dan alat tulis.
Teknik analisa data pada penelitian ini menggunakan model Miles dan Huberman yang meliputi tiga tahap, yaitu reduksi data, penyajian data, dan verifikasi. Teknik pemeriksaan data menggunakan metode triangulasi sumber.

Penelitian ini memiliki keterbatasan yaitu Penelitian ini hanya dilakukan kurang lebih satu bulan untuk melakukan evaluasi pelaksanaan sistem pelaporan rekam medis di klinik Asri Medical Center. Penelitian ini hanya sebatas melakukan evaluasi dan pada akhir penelitian diketahui hasil evaluasi sistem pelaporan saja. Peneliti belum bisa melihat feed back dari hasil evaluasi yang dilakukan oleh peneliti karena keterbatasan waktu yang dimiliki oleh peneliti. Selain itu, penelitian ini bersifat kualitatatif sehingga subyektivitas informan sangat tinggi.

\section{HASIL DAN PEMBAHASAN}

\section{Karakteristik Informan}

Penelitian ini ada dua jenis informan, yaitu informan utama dan informan penunjang. Informan utama dalam penelitian ini terdiri dari dua orang karyawan dan satu orang informan penunjang sebagai sumber informasi untuk menguji kredibilitas hasil wawancara dengan informan utama, yaitu sekretaris medis.

Tabel 1. Karakteristik Informan

\begin{tabular}{|l|l|l|l|l|}
\hline No. & Nama & Jabatan & Pendidikan & Masa Kerja \\
\hline 1. & $\begin{array}{l}\text { Informan } \\
\text { Utama I }\end{array}$ & $\begin{array}{l}\text { Petugas } \\
\text { Rekam } \\
\text { Medis }\end{array}$ & D III & 3 Tahun \\
\hline 2. & $\begin{array}{l}\text { Informan } \\
\text { Utama 2 }\end{array}$ & $\begin{array}{l}\text { Petugas } \\
\text { Front } \\
\text { Officel } \\
\text { Pendaftaran }\end{array}$ & D III & 4 Tahun \\
\hline 3. & $\begin{array}{l}\text { Informan } \\
\text { Penunjang }\end{array}$ & $\begin{array}{l}\text { Sekretaris } \\
\text { Medis }\end{array}$ & S 1 & 2 Tahun \\
\hline
\end{tabular}

\section{Jenis Pelaporan di klinik Asri Medical Center}

Jenis pelaporan yang ada di klinik Asri Medical Center adalah laporan kunjungan rawat jalan, rawat inap dan UGD. Penjabaran jenis laporan yang ada di klinik Asri Medical Center adalah laporan kunjungan pasien rawat jalan, rawat inap dan UGD, laporan sepuluh besar penyakit rawat jalan, laporan indeks penyakit, perhitungan statistik rumah sakit untuk rawat inap. 


\section{Alur Penyusunan Pelaporan di klinik Asri Medical Center}

Alur penyusunan pelaporan dilakukan dengan mengumpulkan data setiap hari, hasil dari pengumpulan data setiap hari ini disebut data harian, data harian yang dikumpulkan direkap mingguan, bulanan, triwulan, dan setiap akhir tahun direkap tahunan.

\section{Permasalahan Sistem Pelaporan di Klinik Asri Medical Center}

Permasalahan dalam sistem pelaporan di klinik Asri Medical Center yaitu terdapat selisih jumlah laporan kunjungan pasien antara laporan yang ada di bagian rekam medis dengan di front office. Laporan kunjungan di bagian rekam medis dibuat berdasarkan penegakan diagnosis dokter, jadi ketika dokter menulis diagnosis di berkas rekam medis pasien maka pasien tersebut dimasukkan ke dalam laporan kunjungan. Kalau di bagian front office laporan kunjungan dan pengunjung dijadikan satu, ini maksudnya kalau pasien mendaftar tetapi tidak jadi periksa maka tetap dimasukkan ke laporan kunjungan.
Kalau di rekam medis jika pasien tidak jadi periksa maka diagnosis tidak ditegakkan maka pasien tersebut dihapus dari laporan kunjungan.

Laporan UGD juga terdapat permasalahan yaitu dokter atau tenaga kesehatan yang bertugas jaga di UGD tidak menanyakan identitas pasien secara lengkap dan tidak menuliskan tanggal periksa sehingga menyulitkan petugas dalam merekap laporan. Untuk laporan rawat inap juga terjadi permasalahan yaitu petugas yang berjaga dirawat inap belum paham untuk mengisi sensus harian, sehingga petugas rekam medis mengisi sensus harian sendiri sambil wawancara dengan perawat.

\section{Evaluasi Sistem Pelaporan di Klinik Asri Medical Center}

Pada penelitian ini, peneliti menggunakan model evaluasi Health Metrics Network (HMN) dari WHO tahun 2008. Peneliti melakukan evaluasi sistem pelaporan berdasarkan kerangka evaluasi HMN yang sudah disesuaikan dengan kebutuhan peneliti. Kerangkan evaluasi yang digunakan oleh peneliti yaitu:

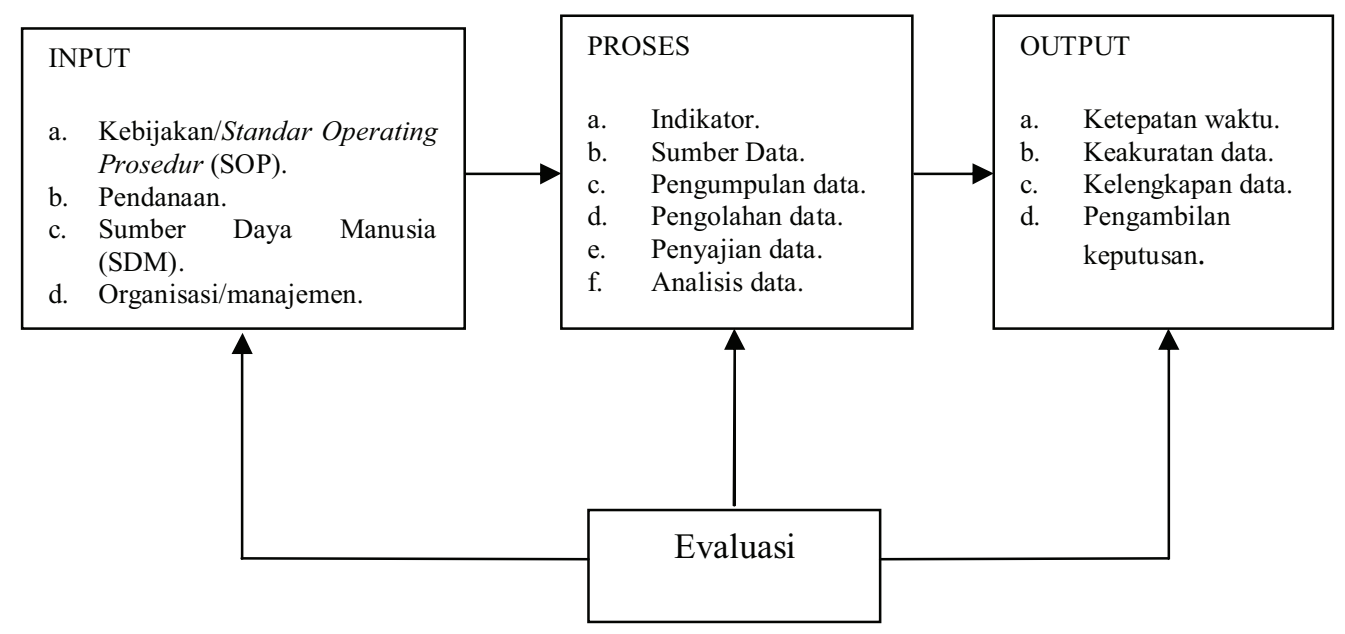

Gambar 1. Kerangka Evaluasi Health Metrics Network

\section{Evaluasi Sistem Pelaporan Dilihat dari Segi Input}

Peneliti mengevaluasi lima aspek dari segi input, yaitu kebijakan/Standar Operating Prosedur (SOP), pendanaan, sumber daya manusia (SDM), organisasi/manajemen dan teknologi.

- Kebijakan/ Standar Operating Prosedur (SOP) Menurut hasil wawancara dengan ketiga informan, di klinik Asri Medical Center terdapat SOP, di dalam SOP mengatur mengenai penyusunan pelaporan. Pelaksanaan penyusunan pelaporan menurut ketiga informan sudah sesuai dengan SOP.

- Pendanaan

Berdasarkan hasil wawancara, aspek pendanaan di klinik Asri Medical Center tidak diberikan secara langsung, namun untuk fasilitas penyusunan laporan sudah tersedia, yaitu kertas dan printer. 
Tri Handayani, dkk. Evaluasi Pelaksanaan Sistem Pelaporan Rekam Medis

- $\quad$ Sumber Daya Manusia (SDM)

Di klinik Asri Medical Center untuk penanggungjawab penyusunan pelaporan adalah petugas rekam medis dan front office, belum ada koordinator dalam penyusunan pelaporan. Petugas rekam medis sudah memahami cara penyusunan pelaporannya karena lulusan D3 rekam medis, tetapi untuk petugas front office masih bingung karena bukan berasal dari lulusan D3 rekam medis/lulusan umum.

- Organisasi/Manajemen

Di klinik Asri Medical Center belum ada struktur organisasi di unit rekam medis. Untuk menyelesaikan permasalahan di unit rekam medis dilakukan musyawarah bersama.

- Teknologi

Penyusunan laporan di klinik Asri Medial Center menggunakan billing system atau SIMRS (Sistem Informasi Manajemen Rumah Sakit). Selain menggunakan billing system juga menggunakan program Epi Info untuk menunjang penyusunan laporan 10 besar penyakit.

\section{Evaluasi Sistem Pelaporan Dilihat dari Segi Proses}

- Indikator

Berdasarkan studi dokumentasi, indikator rawat inap di klinik Asri Medical dapat dilihat pada tabel berikut:

Tabel 2. Laporan Indikator Rawat Inap Asri Medical Center Tahun 2012

\begin{tabular}{llll}
\hline No & $\begin{array}{l}\text { Indikator } \\
\text { Rawat Inap }\end{array}$ & Jumlah & $\begin{array}{l}\text { Standar Ideal } \\
\text { Menurut Depkes }\end{array}$ \\
$\mathbf{1}$ & BOR (\%) & 13.5 & $60-85 \%$ \\
$\mathbf{2}$ & LOS(Hari) & 2.26 & $6-9$ hari \\
$\mathbf{3}$ & TOI (Hari) & 14.5 & $1-3$ Hari \\
$\mathbf{4}$ & BTO(Kali) & 15.5 & $40-50$ Kali \\
$\mathbf{5}$ & NDR & 0 & $<25$ per 1000 \\
$\mathbf{6}$ & GDR & 0 & $\leq 45$ per 1000 \\
\hline
\end{tabular}

Sumber: Unit rekam medis klinik Asri Medical Center Tahun 2012

- Sumber data

Berdasarkan hasil studi dokumentasi dan observasi di klinik Asri Medical Center sumber data yang digunakan dalam penyusunan laporan adalah register rawat jalan, rawat inap dan UGD. Untuk menyusun indikator rawat inap, sumber data yang digunakan adalah sensus harian rawat inap.
- Pengumpulan data

Pengumpulan data dilakukan setiap hari. Data-data yang dikumpulkan untuk menyusun pelaporan antara lain: nama, nomor rekam medis, tanggal periksa, poliklinik tujuan, nama dokter, diagnosis, kode ICD 10, tindakan dan kode ICD 9.

- Pengolahan data

Proses pengolahan data di klinik Asri Medical Center sumber data yang menjadi acuan dalam pengolahan data menggunakan register harian. Dari register harian direkap mingguan, kemudian direkap bulanan, triwulan dan rekap tahunan. Kendala pengolahan datanya adalah belum ada penanggungjawab pelaporan dan harus mengutamakan pelayanan. Cara menyelesaikan permasalahan dalam pengolahan data harus ada penanggungjawab pengolahan laporan dan menambah SDM untuk membantu pelayanan.

Berdasarkan hasil observasi, di klinik Asri Medical Center pengolahan data dilakukan dengan cara mengeksport laporan kunjungan pendaftaran dari billing system ke Microsoft Excel. Data yang masuk ke dalam Microsoft Excel ini adalah register kunjungan pasien baik rawat jalan, rawat inap, dan UGD. Data dalam register ini berisi antara lain: nama, nomor rekam medis, tanggal periksa, poliklinik tujuan, nama dokter, diagnosis, kode ICD 10, tindakan dan kode ICD 9 CM. Untuk mengolah laporan, petugas rekam medis memanfaatkan fasilitas editing Sort \& Filter dalam Microsoft Excel.

- Penyajian data.

Penyajian data di klinik Asri Medical Center berupa tabel dan grafik. Petugas menyajikan data dalam bentuk tabel dan grafik karena mudah dibuat.

- Analisis data

Pelaporan yang dibuat oleh petugas rekam medis klinik Asri Medical Center dilakukan analisis. Cara menganalisisnya dilihat laporan setiap bulan apakah jumlah pasiennya naik atau turun.

\section{Evaluasi Sistem Pelaporan Dilihat dari Segi Output}

\section{Ketepatan Waktu}

Ketepatan waktu pengiriman laporan untuk laporan intern tidak dapat diukur, karena belum ada protap yang mengatur. Pengiriman laporan KDRS belum tepat waktu. 


\section{Keakuratan Data}

Laporan yang dibuat oleh petugas rekam medis tidak akurat, karena jumlah kunjungan pasien yang dibuat oleh bagian front office dan rekam medis jumlahnya berbeda.

\section{Kelengkapan data}

Kelengkapan data di klinik Asri Medical Center belum lengkap, karena belum membuat laporan sesuai peraturan Dinas Kesehatan, yang dibuat sesuai ketentuan Dinas Kesehatan baru sebatas laporan KDRS saja.

\section{Pengambilan keputusan}

Laporan yang dibuat digunakan sebagai dasar dalam pengambilan keputusan, yang memanfaatkan laporan adalah bagian keuangan, SDM, bagian medik. Bagian keuangan dan SDM memanfaatkan laporan untuk menghitung jasa medik dokter, perawat, bidan dan tenaga medis yang lain serta menghitung bonus karyawan berupa IPK (Indeks Prestasi Kerja). Bagian SDM memanfaatkan laporan kunjungan pasien untuk menghitung kebutuhan SDM. Direktur medik memanfaatkan laporan untuk menentukan jumlah pembelian bahan habis pakai (BHP), alat-alat kesehatan, dan menentukan penambahan kebutuhan tempat tidur untuk pasien rawat inap.

\section{HASIL DAN PEMBAHASAN}

\section{Evaluasi Sistem Pelaporan Dilihat dari Segi Input}

Dilihat dari segi input, peneliti melakukan evaluasi mengenai kebijakan /standar operating prosedur (SOP), pendanaan, sumber daya manusia (SDM) dan Organisasi /manajemen dan teknologi.

\section{Kebijakan /Standar Operating Prosedur (SOP)}

Di klinik Asri Medical Center terdapat SOP di unit rekam medis, di dalam SOP mengatur mengenai penyusunan pelaporan. Pelaksanaan penyusunan pelaporan menurut ketiga informan sudah sesuai dengan SOP.

\section{Pendanaan}

Di klinik Asri Medical Center dari aspek pendanaan tidak diberikan dana secara langsung tetapi disediakan fasilitas berupa kertas dan printer dari manajemen. Menurut WHO (2008), untuk menyusun sistem informasi kesehatan diperlukan sumber dana dalam menunjang komprehensif sebuah sistem informasi. Hal ini digunakan untuk memberikan dana pada karyawan untuk melakukan pengumpulan data, pelaporan dan analisis data.

\section{Sumber Daya Manusia (SDM)}

Di klinik Asri Medical Center untuk petugas rekam medis sudah memahami cara penyusunan pelaporannya karena lulusan D3 rekam medis, tetapi untuk petugas front office masih bingung karena bukan berasal dari lulusan D3 rekam medis/lulusan umum.

Menurut Hatta (2009), pembinaan dan pengembangan hendaknya dipandang sebagai suatu bagian yang utama dalam manajemen yang strategis di institusi pelayanan kesehatan. Sedangkan dari sisi pendanaan/anggaran bertujuan untuk meningkatkan produktivitas, tingkat kinerja yang baik dan menguntungkan. Upaya yang dapat dilakukan adalah melalui pendidikan dan pelatihan. Manfaat pendidikan dan pelatihan dapat membantu organisasi dalam mencapai tujuan, baik dari segi individu, kelompok maupun organisasi. Pembinaan dan pengembangan hendaknya dipandang sebagai suatu rangkaian yang dimulai dari orientasi. Melalui proses yang panjang pembinaan dan pengembangan menuju pengembangan karier staf. Jadi bagaimanapun juga investasi dalam pengembangan SDM tidak berakhir hanya dengan pelatihan.

\section{Organisasi /Manajemen}

Di klinik Asri Medical Center belum ada struktur organisasi dalam unit rekam medis. Menurut Budi (2011), unit rekam medis sebagai salah satu organisasi organisasi pendukung kegiatan di fasilitas pelayanan kesehatan. Untuk memperlancar pengelolaan kegiatan di unit rekam medis dibentuk struktur organisasi unit rekam medis.

\section{Teknologi}

Teknologi di klinik Asri Medical Center sudah menggunakan billing system dalam menyusun laporan. Selain itu, penyusunan laporan juga didukung program Epi Info.

Menurut Aderson, dkk (1994) teknologi sistem informasi mendukung organisasi yang sangat komplek. Institusi pelayanan kesehatan berada di bawah tekanan dari penerima jasa /customer untuk meningkatkan keuntungan rumah sakit. Oleh karena itu, sistem informasi kesehatan sangat diperlukan untuk bersaing dengan pemberi pelayanan kesehatan untuk meningkatkan keuntungan financial organisasi. 


\section{Evaluasi Sistem Pelaporan Dilihat dari Segi Proses}

Dilihat dari segi proses, peneliti melakukan evaluasi mengenai indikator, sumber data, pengumpulan data, pengolahan data, analisa data dan penyajian data.

\section{Indikator}

Analisa indikator pelayanan rawat inap di klinik Asri Medical Center Tahun 2012 dapat dilihat pada tabel berikut:

Tabel 3. Analisa Indikator Rawat Inap klinik Asri Medical Center Tahun 2012

\begin{tabular}{|c|c|c|c|}
\hline $\begin{array}{l}\text { Indika- } \\
\text { tor }\end{array}$ & Hasil & $\begin{array}{l}\text { Standar } \\
\text { Ideal } \\
\text { Menurut } \\
\text { Depkes }\end{array}$ & Interpretasi\&Analisa \\
\hline $\begin{array}{l}\text { BOR } \\
(\%)\end{array}$ & $13.5 \%$ & $60-85 \%$ & $\begin{array}{l}\text { Pada tahun } 2012 \text { rata-rata } \\
\text { pemakaian tempat tidur } \\
\text { sebesar } 13.5 \% \text { sehingga } \\
\text { belum efisien. }\end{array}$ \\
\hline $\begin{array}{l}\text { LOS } \\
\text { (hari) }\end{array}$ & 2.26 & $6-9$ & $\begin{array}{l}\text { Pada tahun } 2012 \text { rata-rata } \\
\text { lamanya pasien dirawat } \\
2.26 \text { hari sehingga belum } \\
\text { efisien. }\end{array}$ \\
\hline $\begin{array}{l}\text { TOI } \\
\text { (hari) }\end{array}$ & $\begin{array}{l}14.5 \\
\text { hari }\end{array}$ & $1-3$ & $\begin{array}{l}\text { Pada tahun } 2012 \text { rata-rata } \\
\text { interval pemakaian tempat } \\
\text { tidur } 14.5 \text { hari sehingga } \\
\text { belum efisien. }\end{array}$ \\
\hline $\begin{array}{l}\text { BTO } \\
\text { (kali) }\end{array}$ & $\begin{array}{l}15.5 \\
\text { kali }\end{array}$ & $40-50$ & $\begin{array}{l}\text { Pada tahun } 2012 \text { rata-rata } \\
\text { pasien keluar sebanyak } \\
15.5 \text { pasien sehingga belum } \\
\text { efisien. }\end{array}$ \\
\hline $\begin{array}{l}\text { NDR } \\
(\%)\end{array}$ & 0 & $\leq 25$ & $\begin{array}{l}\text { Pada tahun } 2012 \text { belm ada } \\
\text { kasus pasien meninggal }>48 \\
\text { jam dirawat. }\end{array}$ \\
\hline $\begin{array}{l}\text { GDR } \\
(\%)\end{array}$ & 0 & $\leq 45$ & $\begin{array}{l}\text { Pada tahun } 2012 \text { belum ada } \\
\text { kasus pasien meninggal. }\end{array}$ \\
\hline
\end{tabular}

\section{Sumber Data}

Sumber data yang digunakan untuk menyusun laporan adalah buku register rawat jalan, rawat inap, dan UGD serta sensus harian rawat inap. Menurut WHO (2008), pengumpulan data secara rutin dapat diperoleh dari buku register, laporan indeks pasien, dan sensus harian. Jadi dapat disimpulkan bahwa sumber data yang digunakan untuk menyusun laporan sudah sesuai dengan teori.

\section{Pengumpulan data}

Pengumpulan data di klinik Asri Medical Center dilakukan setiap hari. Menurut WHO (2008), pengumpulan dan pengambilan data dalam jangka menengah dan panjang harus valid (akurat, tepat waktu, lengkap dan dapat dipercaya), dapat digunakan untuk menganalisis trend penyakit, dapat digunakan dalam menilai peningkatan pelayanan, dapat digunakan untuk membandingkan perbedaan cara pelayanan, dan dapat digunakan untuk menentukan persebaran penyakit.

\section{Pengolahan data}

Proses pengolahan data memanfaatkan fasilitas biling system kemudian data diolah menggunakan Microsoft Excel.

Pengolahan data dapat dilakukan menggunakan tangan (manual) maupun menggunakan alat elektronik, sehingga akan menghasilkan keluaran (output). Pengolahan data di klinik Asri Medical Center menggunakan komputerisasi dan sudah sesuai dengan teori dari Rustiyanto (2010).

\section{Penyajian data}

Penyajian data di klinik Asri Medical Center berupa tabel dan grafik. Menurut Rustiyanto (2010), data statistik seharusnya disajikan dengan cara yang mudah dicermati, menarik dan membuat data mudah untuk dipahami dan digunakan. Penyajian data terdiri dari tabel yang sederhana untuk mengerjakan grafik dengan teliti.

\section{Analisa data}

Pelaporan yang dibuat sudah dilakukan analisis dengan cara menganalisis laporan kunjungan setiap bulan. Jadi di klinik Asri Medical Center menitikberatkan analisis dari segi naik-turunnya jumlah pasien berdasarkan laporan kunjungan pasien. Untuk analisis kuantitatif dan kualitatif belum dilakukan. Jadi belum sesuai dengan teori Hatta (2009), yaitu rekam medis harus dianalisis dengan cara kualitatif dan kuantitatif.

\section{Evaluasi Sistem Pelaporan Dilihat dari Segi Output}

Dilihat dari segi output, peneliti melakukan evaluasi mengenai ketepatan waktu, keakuratan data, kelengkapan data dan pengambilan keputusan.

\section{Ketepatan waktu}

Pengiriman laporan berupa ketepatan waktu tidak bisa dihitung/diukur untuk laporan internalnya karena belum ada aturan/protap yang mengatur mengenai waktu pengiriman laporan. Laporan eksternal berupa KDRS waktu pengiriman maksimal 1x24 jam setelah diagnosis terakhir ditegakkan. 


\section{Keakuratan data}

Laporan yang dibuat oleh petugas rekam medis tidak akurat. Menurut Budi (2011) untuk menjalankan pekerjaan di rekam medis diperlukan sumber daya manusia yang memenuhi kompetensi perekam medis. Di klinik Asri Medical Center untuk bagian front office (pendaftaran) belum ada lulusan D3 rekam medis sebaiknya ada penempatan D3 rekam medis di front office agar laporan/data yang dihasilkan menjadi akurat.

\section{Kelengkapan data}

Kelengkapan data di klinik Asri Medical Center belum lengkap karena belum membuat laporan sesuai peraturan Dinas Kesehatan, yang dibuat sesuai ketentuan Dinas Kesehatan baru sebatas laporan KDRS saja. Tetapi mulai tahun 2013 klinik Asri Medical Center mulai merintis melengkapi pelaporan sesuai ketentuan dari Dinas Kesehatan karena pada bulan Maret 2013 Dinas Kesehatan Kota Yogyakarta mewajibkan untuk mengirim laporan.

Kelengkapan pengumpulan data sangat penting karena dapat digunakan untuk berbagai keperluan. Oleh karena itu, klinik Asri Medical Center sebaiknya melengkapi penyusunan laporan rekam medis.

\section{Pengambilan keputusan}

Laporan yang dibuat digunakan sebagai dasar dalam pengambilan keputusan, yang memanfaatkan laporan adalah bagian keuangan, SDM, bagian medik.

Menurut WHO (2008), informasi digunakan oleh berbagai tingkat/level dalam sistem kesehatan untuk pelayanan kesehatan, dan sistem manajemen, perencanaan, dan pengembangan. Salah satu fungsi penting dalam sistem informasi kesehatan adalah menghubungkan hasil analisa data dengan kegunaannya.

Berdasarkan uraian di atas, dapat disimpulkan bahwa laporan yang dibuat oleh unit rekam medis klinik Asri Medical Center telah dimanfaatkan sebagai dasar dalam pengambilan keputusan. Yang memanfaatkan laporan dari unit rekam medis adalah bagian keuangan, SDM, dan bagian medis.

\section{SIMPULAN}

Jenis pelaporan di klinik Asri Medical Center belum sesuai ketentuan Permenkes RI nomor 1171 Tahun 2011 tentang Sistem Informasi Rumah Sakit.

Alur penyusunan pelaporan di klinik Asri Medical Center sudah sesuai dengan teori.
Permasalahan sistem pelaporan di klinik Asri Medical Center meliputi penyusunan laporan pengunjung dan kunjungan pasien, penyusunan laporan UGD dan pelaksanaan pengisian sensus harian rawat inap.

Evaluasi sistem pelaporan di klinik Asri Medical Center, dari segi input di klinik Asri Medical Center sudah ada SOP penyusunan laporan namun belum ada juknis penyusunan laporan, dari segi pendanaan tidak diberikan dana secara langsung, namun diberi fasilitas untuk menyusun laporan, petugas rekam medis sudah memahami cara menyusun pelaporan namun petugas front office belum memahami, struktur organisasi di unit rekam medis belum ada, dari segi teknologi sudah memanfaatkan billing system dalam menyusun laporan. Evaluasi dari segi proses, indikator rawat inap belum efisien, sumber data penyusunan laporan sudah sesuai dengan teori, pengumpulan, pengolahan, penyajian dan analisis data sudah dilakukan namun analisis data belum sesuai teori. Dari segi output, pengiriman laporan KDRS belum tepat waktu, laporan yang dibuat belum akurat dan lengkap, pengambilan keputusan sudah memanfaatkan laporan.

\section{DAFTAR PUSTAKA}

Budi, Savtri Citra. 2011. Manajemen Unit Kerja Rekam Medis. Yogyakarta: Quantum Sinergis Media

Hatta, Gemala. 2009. Pedoman Manajemen Informasi Kesehatan di Sarana Pelayanan Kesehatan. Jakarta: UI Press

Permenkes, RI. 2011. Permenkes nomor 1171 tahun 2011 tentang Sistem Informasi Rumah Sakit

Permenkes, RI. 2011. Permenkes nomor 28 tahun 2011 tentang Klinik

Rustiyanto, Ery. 2010. Statistik Rumah Sakit untuk PengambilanKeputusan. Yogyakarta: GrahaIlmu

Undang-Undang Nomor 14 Tahun 2008 tentang Keterbukaan Informasi Publik (KIP).

Undang-Undang Nomor 44 tahun 2009 tentang Rumah Sakit.

WHO. 2008. Framework and Standards for Country Health Information Sistems Second Edition. Avenue Appia Geneva Switzerland Diunduh dari http://www.healthmetricsnetwork.org. pada tanggal 25 Maret 2013 pukul 07.56 